\title{
The difficult balance between scientific evidence and clinical practice: the 2016 ESSKA meniscus consensus on the surgical management of degenerative meniscus lesions
}

\author{
R. Seil ${ }^{1,2} \cdot$ Jon Karlsson $^{3} \cdot$ P. Beaufils ${ }^{4} \cdot$ R. Becker ${ }^{5} \cdot$ S. Kopf $^{6} \cdot$ M. Ollivier ${ }^{4} \cdot$ M. Denti ${ }^{7}$
}

Published online: 27 February 2017

(C) European Society of Sports Traumatology, Knee Surgery, Arthroscopy (ESSKA) 2017

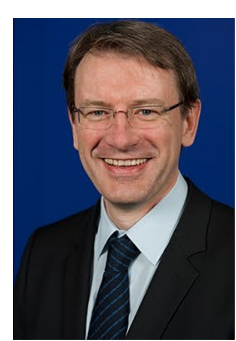

R. Seil

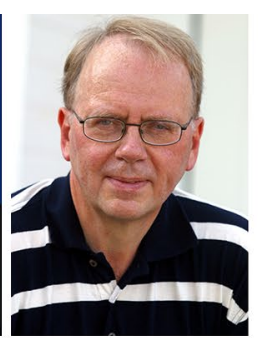

Jon Karlsson

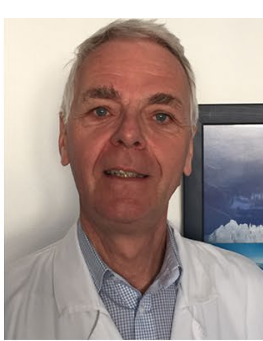

P. Beaufils

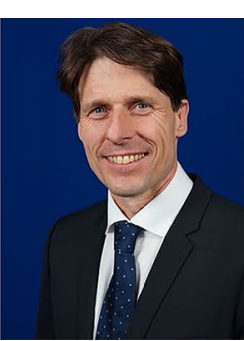

R. Becker

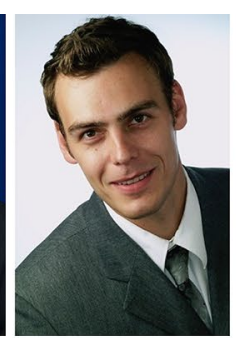

S. Kopf

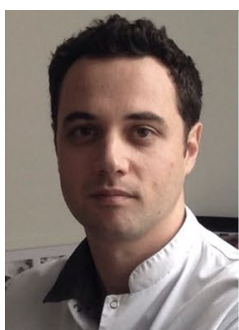

M. Ollivier

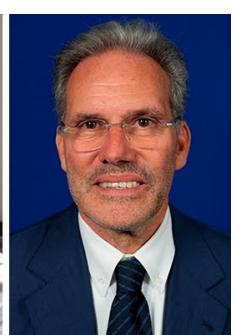

M. Denti
Arthroscopic partial meniscectomy is one of the most popular orthopaedic procedures, especially for degenerative meniscus lesions (DML). However, all recently published randomized controlled trials (RCT) [1-6] except one [7] demonstrated no additional benefit of arthroscopic partial meniscectomy compared to non-operative treatment. This stimulated an intense and controversial global debate which was not necessarily useful to clinicians in their daily clinical practice [8-10]. Despite this high-level scientific

\author{
R. Seil \\ rseil@yahoo.com \\ Jon Karlsson \\ jon.karlsson@telia.com \\ P. Beaufils \\ pbeaufils@ch-versailles.fr \\ R. Becker \\ roland_becker@yahoo.de \\ S. Kopf \\ Sebastian.Kopf@charite.de \\ M. Denti \\ matteo@denti.ch.it
}

Département de l'Appareil Locomoteur, Centre Hospitalier de Luxembourg-Clinique d' Eich, 78, Rue d'Eich,

1460 Luxembourg, Germany evidence, they claimed that patients which were included in these RCT's represent only a minority of those seeking advice for painful knees in association with DML. This is in accordance with the findings of ESSKA's former president Lars Engebretsen and his team in relation with cartilage injuries. Our Norwegian colleagues found that patients qualifying for inclusions in RCT's represented only $4 \%$ of the patients they saw in their cartilage clinic [11]. Although there are no exact figures for DML, clinical experience

2 Sports Medicine Research Laboratory, Luxembourg Institute of Health, 78, Rue d'Eich, 1460 Luxembourg, Germany

3 Department of Orthopaedics, Sahlgrenska University Hospital, Molndal, Sweden

4 Orthopaedics Department, Centre Hospitalier de Versailles, 78150 Le Chesnay, France

5 Department of Orthopaedics and Traumatology, Hospital Brandenburg, Medical School Theodor, Fontane, Hochstrasse 26, 14770 Havel, Brandenburg, Germany

6 Center for Musculosketal Surgery, Charité-University Medicine Berlin, AugustenburgerPlatz, 1, 13353 Berlin, Germany

7 Galeazzi Orthopaedic Institute, Milan, Italy 
supports the hypothesis that the situation is similar in the context of DML. Therefore, there appeared to be a need for a more uniform and clear message, balancing these two controversial opinions.

Ideally, the treatment of DML should be related to both scientific evidence and clinical expertise. In an editorial published 2 years ago in the same journal, Beaufils wrote "this rose the necessity of a consensual process, founded on the independence of the organizers and with the participation of all interested parties to produce the most exhaustive critical analysis of the literature possible [12]. Work of this kind will permit a probable reduction in the number of arthroscopic meniscal resections in our countries in favor of abstention and meniscal repair and an improved nosological definition of the meniscectomy, rendering it pertinent and efficient." This process, which was called the "ESSKA Meniscus Consensus Project" was initiated by the ESSKA Board after the ESSKA congress in Amsterdam in 2014. The goal of the initiative was to find a European consensus on the treatment of degenerative meniscal pathologies. Finding a consensus in such a diverse continent like Europe where medical culture and healthcare systems vary from country to country is not easy. A strict methodology has, therefore, been applied, and 84 European physicians, surgeons, and scientists from 22 countries have been involved in this process. The goal was to propose a framework rather than strict guidelines.

The outcome of this process is presented in the current edition of KSSTA [13]. As it could have been anticipated among experienced clinicians, the initiative resulted in a wide consensus among European peers, in the sense that arthroscopic partial meniscectomy should not be proposed as a first line of treatment of DML, which should always be started non-operatively. It is only after a failure of the latter that an arthroscopic partial meniscectomy should be envisaged. In addition to this, it was emphasized that magnetic resonance imaging is not indicated as a first-line diagnostic tool. Standard knee radiographs are still recognized as the first imaging procedure, mainly to rule out underlying osteoarthritis.

However, the initiative did also identify some limitations of our current understanding of DML. Further work needs to be done with respect to the causative factor of knee pain associated to DML. Perimeniscal synovitis is a well-known cause $[14,15]$, but neither the size, nor the type or the location of the structural lesion of the meniscal tissue, nor the mechanical symptoms have been exactly defined so far. They may be key factors in the surgical decision-making process influencing the current controversial debate.

We hope that these recommendations will deliver a clear message to the orthopaedic community, avoiding any conflicting or political statements, and providing a well-balanced treatment algorithm with a place for both non-operative and arthroscopic treatment in the orthopaedic armamentarium. As further evidence will be added to the current understanding of the problem, the consensus may be modified in the future.

\section{References}

1. Herrlin S, Hållander M, Wange $\mathrm{P}$, Weidenhielm L, Werner S (2007) Arthroscopic or conservative treatment of degenerative medial meniscal tears: a prospective randomised trial. Knee Surg Sports Traumatol Arthrosc 15(4):393-401

2. Herrlin SV, Wange PO, Lapidus G, Hållander M, Werner S, Weidenhielm L (2013) Is arthroscopic surgery beneficial in treating non-traumatic, degenerative medial meniscal tears? A five year follow-up. Knee Surg Sports Traumatol Arthrosc 21(2):358-364

3. Katz JN, Brophy RH, Chaisson CE et al (2013) Surgery versus physical therapy for a meniscal tear and osteoarthritis. N Engl J Med 368(18):1675-1684

4. Kirkley A, Birmingham TB, Litchfield RB et al (2008) A randomized trial of arthroscopic surgery for osteoarthritis of the knee. N Engl J Med 359(11):1097-1107

5. Moseley JB, O'Malley K, Petersen NJ (2002) A controlled trial of arthroscopic surgery for osteoarthritis of the knee. N Engl J Med 347(2):81-88

6. Sihvonen R, Paavola M, Malmivaara A et al (2013) Arthroscopic partial meniscectomy versus sham surgery for a degenerative meniscal tear. N Engl J Med 369(26):2515-2524

7. Gauffin H, Tagesson S, Meunier A, Magnusson H, Kvist (2014) Knee arthroscopic surgery is beneficial to middle-aged patients with meniscal symptoms: a prospective, randomised, singleblinded study. Osteoarthr Cartilage 22:1808-1816

8. El Attrache N, Lattermann C, Hannon M, Cole B (2014) New England. Journal of Medicine Article evaluating the usefulness of meniscectomy is flawed. Arthroscopy 30:542-543

9. Lubowitz JH, Provencher MT, Rossi MJ (2014) Could the New England. Journal of Medicine be biased against arthroscopic knee surgery? Arthroscopy 30(6):654-655

10. Rossi MJ, D’Agostino RB Jr, Provencher MT, Lubowitz JH (2014) Could the New England. Journal of Medicine be biased against arthroscopic knee surgery? Arthroscopy 30(5):536-537

11. Engen N, Engebretsen L, Årøen A (2010) Knee cartilage defect patients enrolled in randomized controlled trials are not representative of patients in orthopedic practice. Cartilage 1:312-319

12. Beaufils P, Becker R, Verdonk R, Aagaard H, Karlsson J (2015) Focusing on results after meniscus surgery. Knee Surg Sports Traumatol Arthrosc 23:3-7

13. Beaufils P, Becker R, Kopf S, Englund M, Verdonk R, Ollivier M, Seil R, European Society of Sports Traumatology, Knee Surgery and Arthroscopy (2017) The surgical management of degenerative meniscus lesions: the 2016 ESSKA meniscus consensus. Knee Surg Sports Traumatol Arthrosc. doi:10.1007/ s00167-016-4407-4

14. Tornbjerg SM, Nissen N, Englund M et al (2016) Structural pathology is not related to patientreported pain and function in patients undergoing meniscal surgery. $\mathrm{Br} \mathrm{J}$ Sports Med. doi:10.1136/bjsports-2016-096456

15. Scanzello CR, McKeon B, Swaim BH et al (2011) Synovial inflammation in patients undergoing arthroscopic meniscectomy: molecular characterization and relationship to symptoms. Arthritis Rheum 63:391-400 